\title{
Driving Behavior and Traffic Safety: An Acceleration-Based Safety Evaluation Procedure for Smartphones
}

\author{
Rosolino Vaiana ${ }^{1}$, Teresa Iuele ${ }^{1}$, Vittorio Astarita ${ }^{1}$, Maria Vittoria Caruso ${ }^{1}$, Antonio Tassitani $^{1}$, Claudio Zaffino ${ }^{1}$ \\ \& Vincenzo Pasquale Giofrè ${ }^{1}$ \\ ${ }^{1}$ Department of Civil Engineering, University of Calabria, Arcavacata di Rende, Cosenza, Italy \\ Correspondence: Teresa Iuele, Department of Civil Engineering, University of Calabria, Via P. Bucci, Cubo 46B, \\ 87036, Arcavacata di Rende, Cosenza, Italy. Tel: 39-098-449-6771. E-mail: teresa.iuele@unical.it
}

Received: July 18, $2013 \quad$ Accepted: December 3, $2013 \quad$ Online Published: January 2, 2014
doi:10.5539/mas.v8n1p88
URL: http://dx.doi.org/10.5539/mas.v8n1p88

\begin{abstract}
Traffic safety and energy efficiency of vehicles are strictly related to driver's behavior. The scientific literature has investigated on some specific dynamic parameters that, among the others, can be used as a measure of unsafe or aggressive driving style such as longitudinal and lateral acceleration of vehicle. Moreover, the use of modern mobile devices (smartphones and tablets), and their internal sensors (GPS receivers, three-axes accelerometers), allows road users to receive real time information and feedback that can be useful to increase awareness of drivers and promote safety. This paper focuses on the development of a prototype mobile application that can evaluate the grade of safety that drivers are keeping on the road by measuring of accelerations (longitudinal and lateral) and warning for users when it can be convenient to correct their driving style. The aggressiveness is evaluated by plotting vehicle's acceleration on a g-g diagram specially studied and designed, where horizontal and lateral acceleration is displayed inside areas of "Good Driving Style". Several experimental tests were carried out with different drivers and cars in order to estimate the system accuracy and the usability of the application. This work is part of the wider research project M2M, Mobile to Mobility: Information and communication technology systems for road traffic safety (PON National Operational Program for Research and Competitiveness 2007-2013) which is based on the use of mobile sensor computing systems for giving real-time information in order to reduce risks and to make the transportation system more safe and comfortable.
\end{abstract}

Keywords: driving behavior, vehicle accelerations, traffic safety, g-g diagram, GPS

\section{Introduction}

Traffic safety is strictly related to the behavior of each driver and to its individual variability associated to several parameters such as: age, gender, geographic locations, and other factors. Moreover, driving behavior has a great influence on energy efficiency: the difference in terms of fuel consumption and, consequently of gas emissions, between a safe (or calm) driver and an aggressive one is estimated to be higher than $40 \%$ (Alessandrini et al., 2012). For this reason, in order to reduce the environmental impact due to the road transportation system, in the last few years the idea of educating drivers to adopt an eco-friendly driving style has been promoted.

An eco-friendly and safe driving behavior could be achieved by reducing or avoiding sudden accelerations and rapid brakings in both longitudinal direction and cornering maneuvers (Yamakado et al., 2009).

The evaluation of real driving scenarios is very complex because it's reliant on many closely interconnected variables depending not only on the different type of drivers, but also on the road environment, the traffic characteristics and the categories of road infrastructure. However, driving behavior assessment has been associated to two main dynamic parameters that, among the others, have been proposed in scientific literature as the most significant for a quantitative evaluation of unsafe or aggressive driving style; these parameters are the longitudinal and the lateral accelerations and decelerations (Shaout \& Bodenmiller, 2011; Klauer et al., 2009; Johnson et al., 2011; Paefgen et al., 2012).

By measuring the in-vehicle accelerations in the XY plane it is possible to categorize the driving behavior into two main classes: aggressive drivers and non-aggressive or safe and expert drivers. The driving style of these last ones, in particular, is characterized by the selection of smooth trajectories with a continuous adjustment of the 
acceleration levels in harmony with the operation of the steering wheel that contribute to a significant improvement of the ride comfort for both drivers and passengers. Finally, expert drivers are able to adequately decelerate passing from a straight lane to a curve; in this way, the front wheels are subject to a higher vertical load generating more cornering force and a more effective steering movement, reducing the energy loss and the tire wear due to the rolling resistance phenomenon (Yamakado et al., 2009).

The spread of modern technologies for mobile devices (smartphones, tablet, etc.), together with the development of several applications to exploit their internal sensors (GPS receivers, three-axes accelerometers), allow road users to receive real time information and feedback on their behavior that can be useful to increase divers awareness and promote safety. By providing this kind of interventions during the guide it is estimated a reduction of about $20 \%$ in the average estimated accident number (Paefgen et al., 2012).

In the light of the above mentioned facts, this paper focuses on the development of a prototype mobile application through which vehicle data (position, speed, longitudinal and lateral accelerations) are monitored and recorded in real time; furthermore it allows to send a warning for users when it can be convenient to correct their driving style to be more safe and less aggressive. It is noted that this project was run under the auspices of the research project "M2M - Mobile to Mobility: Information and communication technology systems for road traffic safety" (PON National Operational Program for Research and Competitiveness 2007-2013, co-financed by European Regional Development Fund, FESR). The main objective of this project is giving real-time information on road quality to road users through mobile sensor computing systems in order to reduce risks and to make the transportation system more safe and comfortable.

The paper is organized as follows: Section 2 presents some previous studies about the assessment of the g-g diagram usability for driving style classification. Some details about the used accelerometer data and experimental tests are also specified in Section 2. Section 3 contains the results and a discussion about obtained data; finally, in Section 4 conclusions and some future perspectives are carried out.

\section{Method}

\subsection{Users Driving Style: Safety Margins in the g-g Diagram}

As stated in the previous paragraphs, both longitudinal and lateral accelerations are significant parameters for the evaluation of drivers behavior. The limits of these accelerations are related to the edges of the friction circle (or the ellipse of adherence) (Da Lio et al., 2005) which depend on tire characteristics and road surface condition (Vaiana et al., 2012). In particular, vehicle stability while cornering depends on the balance of the centrifugal force and the friction force that is developed in the contact area between the wheels and the pavement surface.

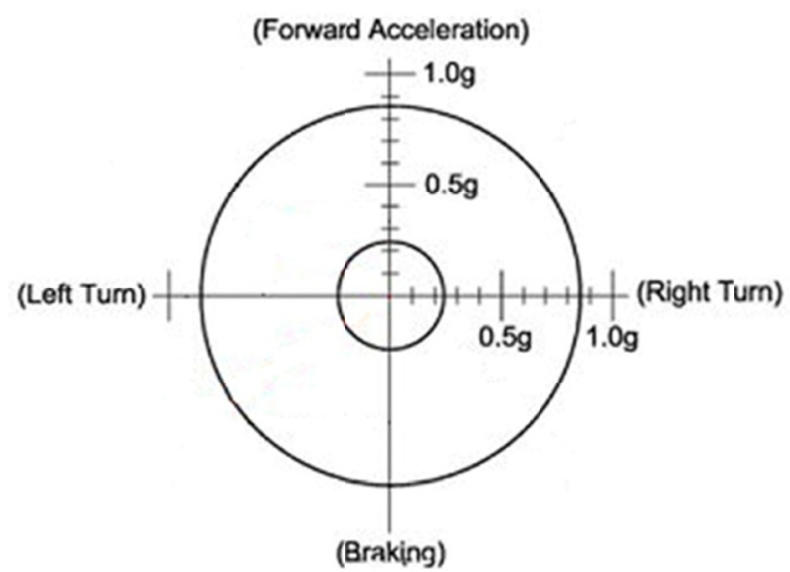

(a)

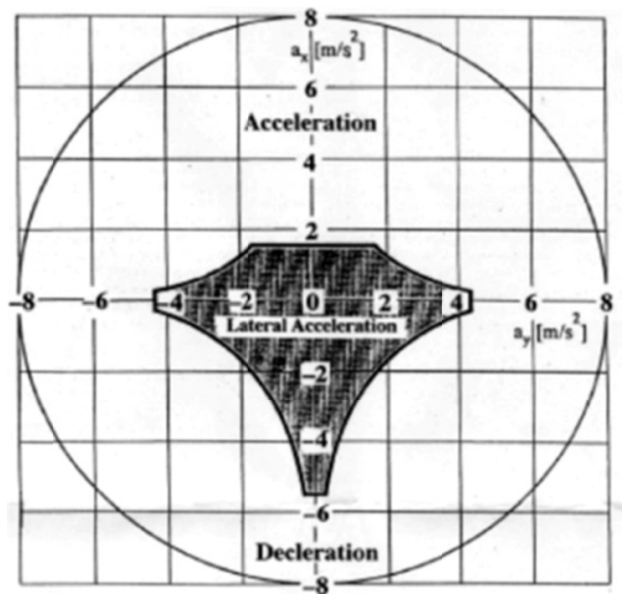

(b)

Figure 1. (a) Friction circle edge; (b) Area of experience and inexperience

The friction force is conventionally broken down into two components: longitudinal friction and transverse friction. When a vehicle is travelling in a straight line only the first one is involved; on the contrary, when the front wheels are turned a transverse force occurs. When both longitudinal and transverse friction occur simultaneously, the resultant force should not be higher than the maximum friction that is represented by the 
edge of the friction circle for specific conditions of surface (dry, wet, icy) and tire (see Figure 1a). On wet roads, friction can be reduced to $30 \%$ compared to dry conditions; the rate of decrease reaches a value of about $90 \%$ for icy surfaces (Andersson et al., 2007). Moreover, the way in which a driver take a corner and the behavior in the approaching straight are influenced by the longitudinal acceleration or deceleration: each driver can choose to take the corner at a constant speed or accelerating and braking in particular sections of the path, in relation to the perceived risk. Also the experience of each driver may be considered a key factor in longitudinal and lateral accelerations variation: the driver acquires capabilities and skills during driving practice that determines a learning effect. Previous researches (Sievert, 1994; Lamm et al., 1999) showed that it is possible to single out an area of driving experience on the g-g diagram (see Figure 1b): an uncommon physical behavior is typical of this area and it is related to vehicle-handling features (forces, torques, etc.).

Furthermore, past studies (Chen et al., 2013; Baldauf et al., 2009; Zhang et al., 2004) showed that vehicle's speed and acceleration are the most significant parameters for the mental workload estimation, among the driving-performance features. In particular, the longitudinal acceleration of the car (increasing and/or decreasing speed) is an indicator of driving task difficulty. When the mental workload becomes too great and it is higher than the driver's ability an accident can occur, affecting traffic safety.

Overlapping the diagram of the driving experience area and the friction circle in an intermediate condition of constrain (wet surface), a new area of safe driving was identified in this study, (see Figure 2a). Some details about the edges of this area are also reported in Figure $2 b$. The new diagram has been named "Driving Style Diagram" (DSD). In particular, the area has a limit of $2.5 \mathrm{~m} / \mathrm{s}^{2}$ for both longitudinal and lateral accelerations (left/right turns); in the case of deceleration the limit value is equal to $3.0 \mathrm{~m} / \mathrm{s}^{2}$. In fact, apart from the tyre grip, other limiting factors, such as the power of the engine, come into play under forward acceleration.

The suitability of the "safe area" edges (as it has been defined) was evaluated by means of a dataset collected during the development of experimental phases of the M2M Project. This dataset was developed considering two different behaviors of a same professional driver; only the longitudinal accelerations were calculated from the GPS readings using the Video-Vbox instrumentation.

The differences in terms of acceleration variability between the aggressive and the safe driving were evaluated in many experimental tests, as shown in Figure 3.

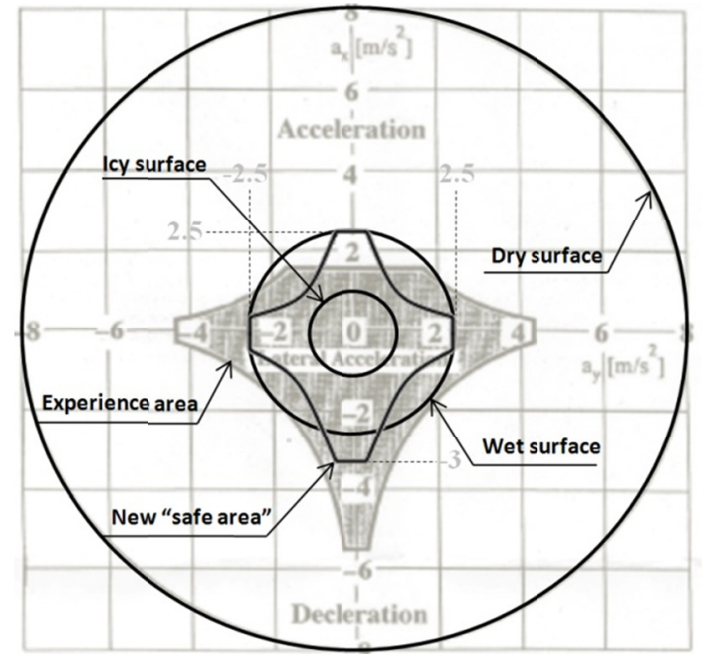

(a)

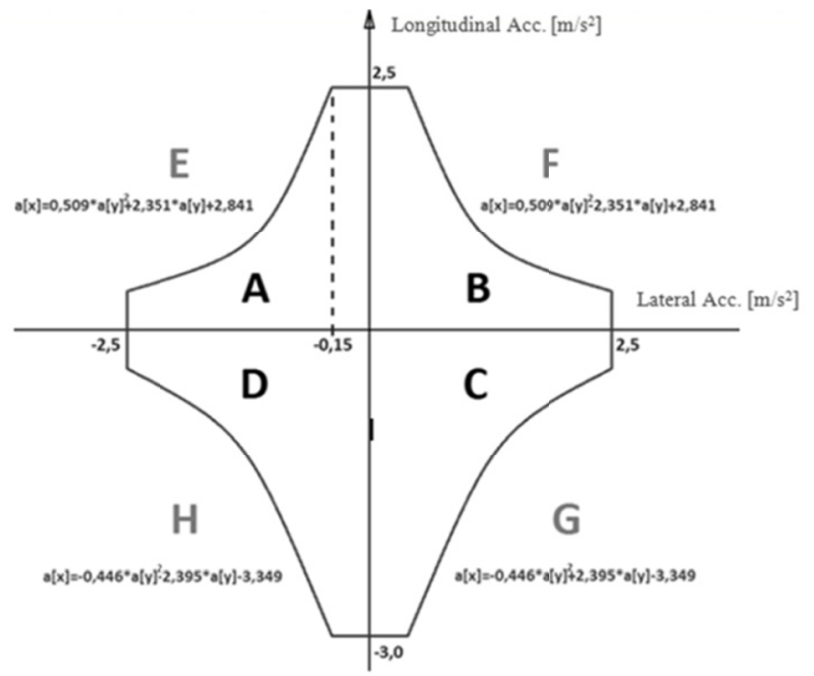

(b)

Figure 2. (a) Construction of the new "safe area"; (b) Driving Style Diagram (DSD $\left[a_{x}-a_{y}\right]$ ) 


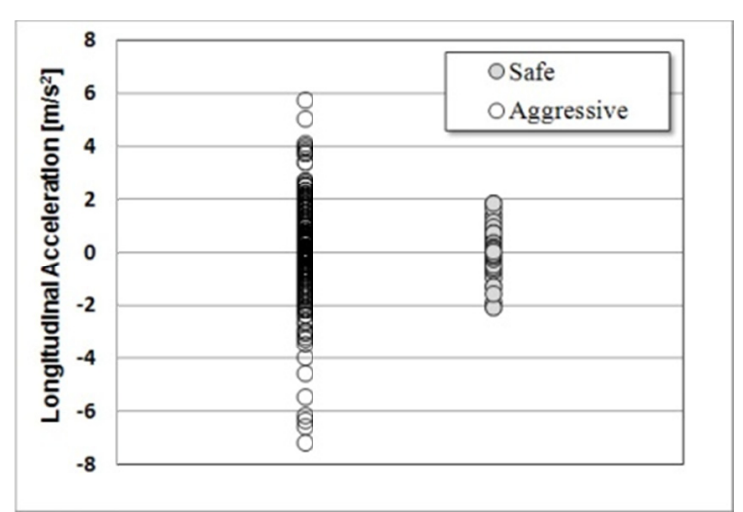

Figure 3. Acceleration variations for both safe and aggressive driving behavior

As it is possible to observe in Figure 3, the safe driving behavior is characterized by acceleration values that range from about $\pm 2 \mathrm{~m} / \mathrm{s}^{2}$; on the contrary, if the driver has an aggressive behavior this limits are doubled. Data were extracted from a dataset of 20 experimental tests carried out on a test site with a length of about $12 \mathrm{~km}$. Results showed in Figure 3 are coherent with the methodology described before (see Figure 2a-2b), in order to evaluate and discriminate different driving styles.

\subsection{Accelerometer Data from GPS}

The GPS module allows to calculate both longitudinal and lateral accelerations as derived parameters. Generally, GPS-based systems record satellite signal-derived speed readings once per second. The longitudinal acceleration can be calculated from consecutive speed measurements using the backward difference method (Jun et al., 2006; Tonzig, 2011):

$$
\text { a_long }=\Delta v / \Delta t
$$

where $\Delta v$ is the speed variation $\left(v_{\text {current }}-v_{\text {previous }}\right)$, while $\Delta t$ is the temporal variation. Moreover, since the GPS has a sampling frequency of $1 \mathrm{~Hz}, \Delta t$ is equal to $1 \mathrm{sec}$. The lateral acceleration, instead, can be expressed as:

$$
\text { a_lat }=v^{2} / R
$$

where $v$ is the current speed value $(\mathrm{m} / \mathrm{s}), R$ is the turn radius $(\mathrm{m})$, which can be evaluate using the expression specified by (Abdulrahim, 2006, Jochem et al., 1995) (Equation 3).

$$
R=(180 \cdot v) /(\pi \cdot \Delta \text { Heading })
$$

where $v$ is the current speed value $(\mathrm{m} / \mathrm{s})$ and $\Delta$ Heading is variation of the heading in the temporal unit. The heading represents the current direction compared to the North direction, expressed as degree with positive rotation with respect to the East. Moreover, the values of this variable is provided directly by the GPS. In this study the Equation (3) was used for the calculation of the instant radius that has to be used in (2), instead of other relationship found in the literature (Carlson et al., 2005; Ibraheem \& Janan, 2011).

Results were compared to acceleration data provided by the Video-Vbox system, a high quality electronic instrument that allows to evaluate speed and both longitudinal and lateral acceleration from a GPS data logger. The validation procedure was satisfactory with differences lower than $1 \%$ between the two sets of values (calculated/derived from the Video-Vbox).

Another validation procedure was carried out on speed data obtained from the GPS readings: derived speed values were compared to those red from the Can network of vehicle through the OBD-II diagnostic port (Figure 4a). Also in this case results show a very high correlation coefficient $\left(\mathrm{R}^{2} \approx 0.99\right)$, as it is possible to observe in Figure 4b. Using acceleration data derived from the GPS readings allows the feasibility of the application to be independent from the position of the device inside the vehicle, avoiding the problems related to the re-orientation of the accelerometer in the $x-y$ plane. 


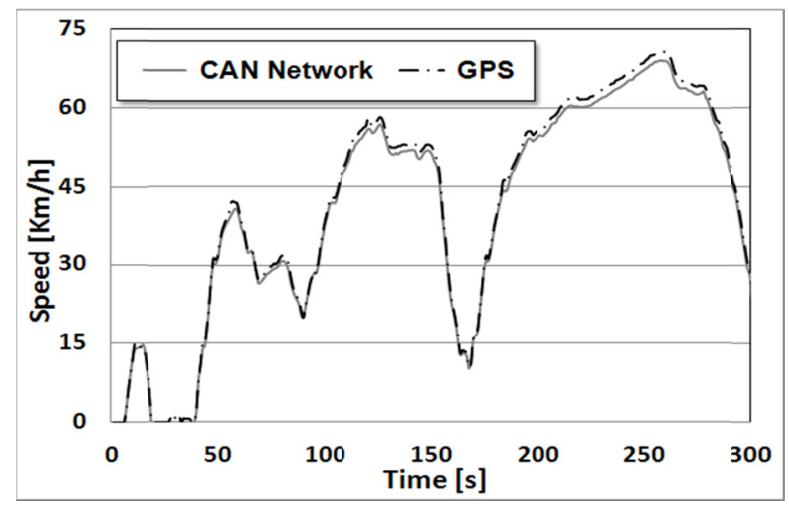

(a)

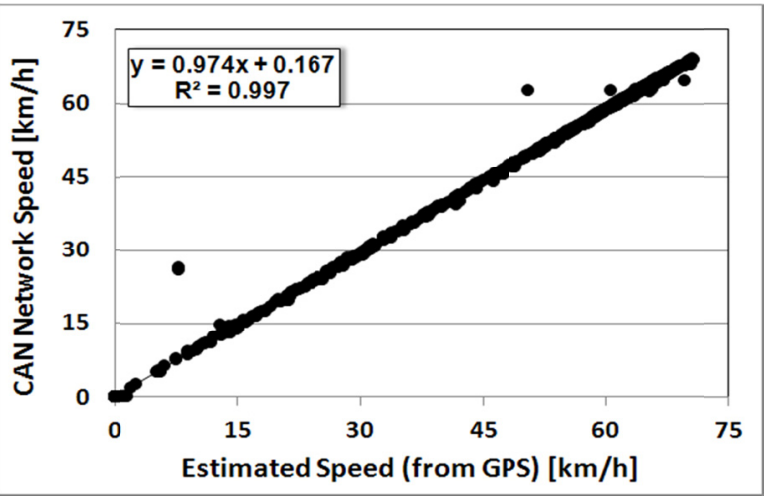

(b)

Figure 4. (a) Comparison between CAN and GPS speed; (b) Correlation between CAN and estimated speed

\subsection{Research Design}

All of experimental tests were carried out on two roads in the district of Cosenza, using one vehicle (Fiat Doblò) and one smartphone (a Samsung Next with Android IO) because very low differences, less than 5\% in terms of position data, were found between many devices in previous studies (Astarita et al., 2012). The device was fixed to the dashboard of vehicle through a rubber and adhesive support.

Five drivers with different driving behavior were recruited among students and professors in the University of Calabria (Italy). Two participants are young drivers with a driving license since 3-4 years, while the other three are 45-50 years old with many years of driving experience. No information about the device working features were given to the participants; however, each one of them knew the main aim of the project in relation to the monitoring of driving behavior.

To identify the aggressive behavior, many potential dangerous events were taken into account:

- $\quad$ excessive speeds, higher than the law limits;

- sudden, intense and repeated brakings and accelerations (detect considering the longitudinal acceleration waveform); aggressive left and right turns;

- $\quad$ aggressive U-turns and roundabout crossing ;

- aggressive lane changes.

The behavior taken in all these situations was agreed as aggressive drivers A, B, D, and for as safe behavior the remainders drivers ( $\mathrm{C}$ and $\mathrm{E})$.

Moreover, the experimental plain included two test sites, both traveled for two round trips (Figure 5): the first has a length of about $15 \mathrm{Km}$, while the second has a length of $18 \mathrm{Km}$; overall, a total of twenty tests were carried out and about $330 \mathrm{Km}$ of road travelled (Figure 5).
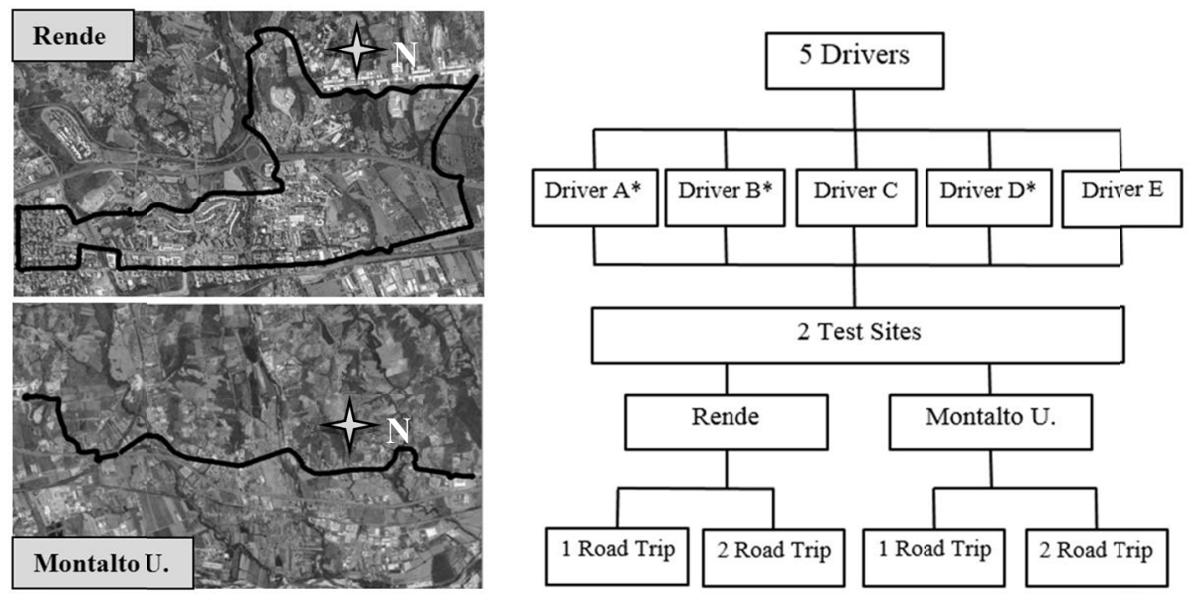

Figure 5. Test sites location and experimental plan 


\section{Results and Discussion}

The behavior of each driver was evaluated by calculating the percentage of points that are characterized by values of accelerations higher than the limiting edges of the DSD area. In particular, the methodology proposed in this study aims to the identification of a specific threshoold of this percentage that allows to differentiate an aggressive driver from a safe one. In this way it is possible to use the proposed mobile application for collecting GPS data, calculating the vehicle's accelerations and giving real-time information to road users about their driving style. In order to reach this purpose the application is set for a systematic control of the accelerations for a specific period of time (i.e. 5 minutes); after this time the calculation restarts and new percentages of external points are estimated with a continuous feedback given to drivers.

The results obtained for the twenty tests carried out in this research are reported in Table 1, in which the drivers, the test sites and the percentage of accelerometer data which fall outside the DSD area are specified. The mean value and the standard deviation of the percentage of external points for each driver were also calculated (Table 1).

Slight differences were found in the estimated percentages for the two tests sites; in particular for the test site located in the city of Rende the aggressive driver is characterized by a mean value of external points of about 13.5 , with a standard deviation of $\pm 1.2 \%$; the safe drivers registered a value of $5.7 \%$. On the contrary, for the test site located in Montalto, registered values are $(11.9 \pm 1.1) \%$ for the aggressive drivers and $(6.1 \pm 0.5) \%$ for the safe ones.

The difference is probably related to the fact that the two tests site are quite different because the first one is characterized by high traffic volumes and it is located in the centre of the city, whereas the other one can be considered a suburban road (lower volumes of traffic, higher operative speeds, etc.).

Table 1. Internal and external percentages of accelerometer data in the DSD (* indicates the aggressive driver)

\begin{tabular}{|c|c|c|c|c|c|c|}
\hline Driver & Test Site & $\begin{array}{c}\text { Test } \\
\text { number }\end{array}$ & $\begin{array}{c}\text { Internal Points } \\
\text { IP [\%] }\end{array}$ & $\begin{array}{l}\text { External } \\
\text { Points } \\
\text { EP [\%] }\end{array}$ & $\begin{array}{l}\text { EP - Mean } \\
\text { Value [\%] }\end{array}$ & $\begin{array}{l}\text { EP - Standard } \\
\text { Deviation [\%] }\end{array}$ \\
\hline \multirow{4}{*}{$\mathrm{A}^{*}$} & \multirow{2}{*}{ Rende } & 1 & 84.7 & 15.3 & \multirow{4}{*}{12.9} & \multirow{4}{*}{ \pm 2.2} \\
\hline & & 2 & 86.0 & 14.0 & & \\
\hline & \multirow{2}{*}{ Montalto U. } & 3 & 89.7 & 10.3 & & \\
\hline & & 4 & 88.0 & 12.0 & & \\
\hline \multirow{4}{*}{$\mathrm{B}^{*}$} & \multirow{2}{*}{ Rende } & 5 & 87.5 & 12.5 & \multirow{4}{*}{12.0} & \multirow{4}{*}{ \pm 0.6} \\
\hline & & 6 & 88.0 & 12 & & \\
\hline & \multirow{2}{*}{ Montalto U. } & 7 & 87.7 & 12.3 & & \\
\hline & & 8 & 88.9 & 11.1 & & \\
\hline \multirow{4}{*}{$\mathrm{C}$} & \multirow{2}{*}{ Rende } & 9 & 94.5 & 5.5 & \multirow{4}{*}{5.5} & \multirow{4}{*}{ \pm 0.8} \\
\hline & & 10 & 95.6 & 4.4 & & \\
\hline & \multirow{2}{*}{ Montalto U. } & 11 & 93.7 & 6.3 & & \\
\hline & & 12 & 94.3 & 5.7 & & \\
\hline \multirow{4}{*}{$\mathrm{D}^{*}$} & \multirow{2}{*}{ Rende } & 13 & 85.8 & 14.2 & \multirow{4}{*}{13.2} & \multirow{4}{*}{ \pm 0.9} \\
\hline & & 14 & 87 & 13.0 & & \\
\hline & \multirow{2}{*}{ Montalto U. } & 15 & 86.5 & 13.5 & & \\
\hline & & 16 & 88.0 & 12.0 & & \\
\hline \multirow{4}{*}{ E } & \multirow{2}{*}{ Rende } & 17 & 92.5 & 7.5 & \multirow{4}{*}{6.3} & \multirow{4}{*}{ \pm 1.0} \\
\hline & & 18 & 94.7 & 5.3 & & \\
\hline & \multirow{2}{*}{ Montalto U. } & 19 & 93.4 & 6.6 & & \\
\hline & & 20 & 94.3 & 5.7 & & \\
\hline
\end{tabular}


On the basis of the results summerized in Table 1, for aggressive drivers the mean value of external points is higher than $10 \%$, whereas the safe drivers registered a percentage lower than $8 \%$. For this reason the threshold value for distinguishing between aggressive and non-aggressive drivers was set to a value of $9 \%$.
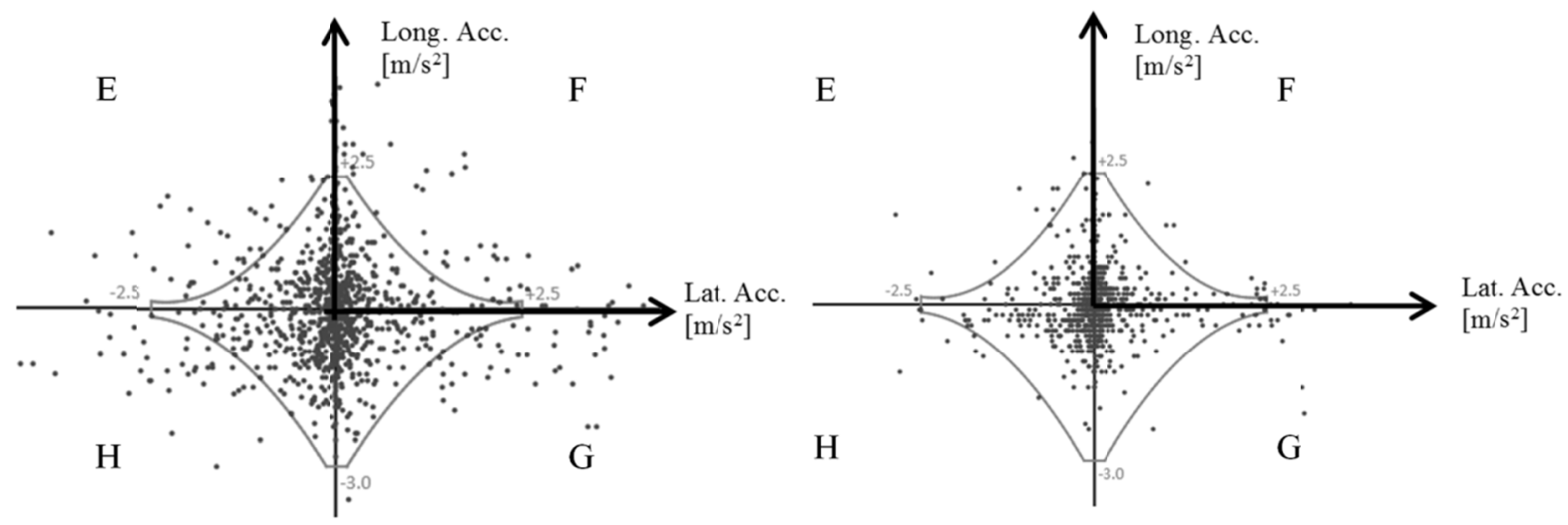

Figure 6. Distribution of points in the DSD for an aggressive driver (left) and a safe one (right)

In Figure 6 it is possible to observe some differences between two DSD for an aggressive and a safe driver; the percentages of points belonging to the four external regions of the diagram $(\mathrm{E}, \mathrm{F}, \mathrm{G}, \mathrm{H})$ are shown in Figure 7 .

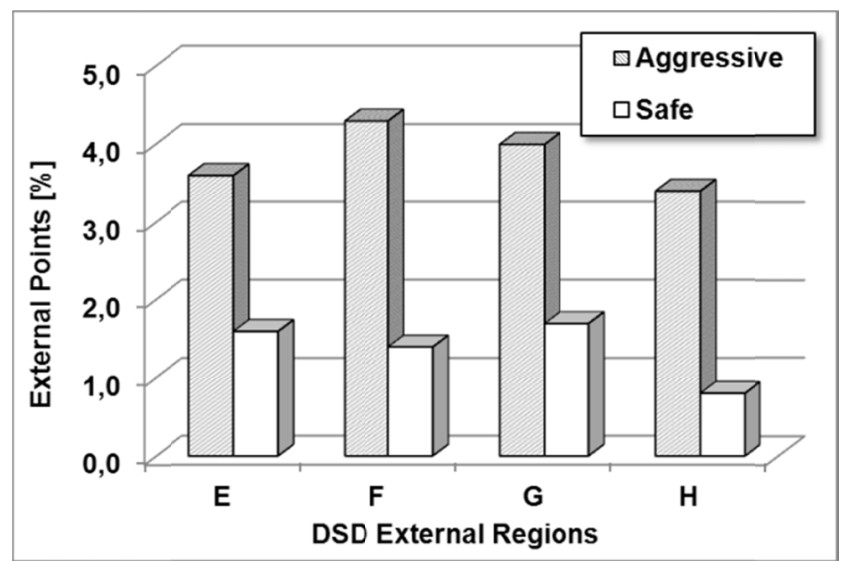

Figure 7. Percentages of external points in the different regions of the DSD

\section{Conclusions}

In this study a methodology for evaluating driving behavior by means of an Android application was developed. In particular, the user's driving style recognition was based on the acceleration values (both longitudinal and lateral) that are derived from GPS position data. The aggressiveness was evaluated by plotting vehicle's accelerations on a g-g diagram, where lateral acceleration is displayed on the horizontal axis and longitudinal acceleration on the vertical one. A detailed investigation on the safety margins to be set for driving style recognition was carried out. Overlapping the diagram of driving experience and the friction circle in an intermediate condition of constrain (wet surface), a new diagram was created, named Driving Safe Diagram, DSD. The behavior of each driver was evaluated by calculating the percentage of points that are characterized by values of accelerations higher than the limiting edges of the DSD area. The proposed procedure allowed to establish a specific threshold for this percentage in order to create a mobile application for a systematic control of vehicle accelerations during a specific period of time with the possibility of giving a continuous feedback to drivers. The mobile application could be developed recording the accelerations by means of the GPS receiver piggybacked on mobile devices. Drivers can be informed about the necessity of modifying their driving style every " $x$ " meters during the trip by following the proposed methodology. The value of $x$ could be calculated starting from the current driving speed. Results showed that the best value for discriminating between aggressive 
and non-aggressive behavior can be set to $9 \%$ of external points. Outcomes of this study are expected to benefit both practitioners and researchers. Moreover, further investigations on different types of roads with higher operative speeds are needed in order to take into account other factors related to the features of the travelled infrastructure. The results presented in this study represent the first prototype of the M2M project. At the end of the project Authors expect a much broader data base that will allow to validate and improve further the results presented in this study.

\section{Acknowledgements}

Authors wish to thank Eng. Francesco Diaz and Eng. Alfredo Imparato for have accommodated our equipment inside the vehicles of FIAT Group S.p.a. (project partners) during certain project activities. Moreover, Authors thank Eng. Francesco De Masi (chief technician of the Laboratory of Road Infrastructures and Materials, Department of Civil Engineering) for the support during the experimental phases.

\section{References}

Abdulrahim, M. (2006). On the dynamic of automobile drifting. Society of automotive engineers 2006-01-1019 (pp. 168-178).

Alessandrini, A., Cattivera, A., Filippi, F., \& Ortenzi, F. (2012). Driving style influence on car $\mathrm{CO}_{2}$ emissions. In 20th International Emission Inventory Conference - "Emission Inventories - Meeting the Challenges Posed by Emerging Global, National, and Regional and Local Air Quality Issues". Tampa, Florida, August 13 16.

Andersson, M., Bruzelius, F., Casselgren, J., Gäfvert, M., Hjort, M., Hultén, J., ... Wälivaara, B. (2007). Road friction estimation. Saab Automobile AB, Trollhättan, Sweden.

Astarita, V., Caruso, M. V., Danieli, G., Festa, D. C., Giofrè, V. P., Iuele, T., \& Vaiana, R. (2012). A mobile application for road surface quality control: UNIquALroad. Procedia: Social \& Behavioral Sciences, Elsevier, 54, 1135-1144. http://dx.doi.org/10.1016/j.sbspro.2012.09.828

Baldauf, D., Burgard, E., \& Wittmann, M. (2009). Time perception as a workload measure in simulated car driving. Applied Ergonomics, 40(5), 929-935.

Carlson, P. J., Burris, M., Black, K., \& Rose, E. R. (2005). Comparison of radius-estimating techniques for horizontal curves. In Transportation Research Record: Journal of the transportation research board, No 1918, TRB, Washington, D.C.

Chen, Z., Huang, Z., Wu, C., Lv, N., \& Ma, J. (2013). Analysis on Vehicle Motion Parameters of Distracted Driving. Improving Multimodal Transportation Systems-Information, Safety, and Integration (ICTIS 2013) (pp. 1692-1697). http://dx.doi.org/0.1061/9780784413036.226

Da Lio, M., Biral, F., \& Bertolazzi, E. (2005). Combining safety margins and user preferences into a driving criterion for optimal control-based computation of reference maneuvers for an ADAS of the next generation. Intelligent Vehicles Symposium. Las Vegas, USA, June 6-8.

Ibraheem, A., \& Janan, F. (2011). Developing a computer program for the methods of radius-Estimating techniques for horizontal curves. American Journal of Engineering and Applied Sciences, 4(2), 276-287.

Jochem, T., Pomerleau, D., Kumar, B., \& Amstrong, J. (1995). PANS: A Portable Navigation Platform. Symposium of Intelligent Vehicles. Detroid, Michigan, USA, September 25-26.

Johnson, D. A., \& Trivedi, M. M. (2011). Driving Style Recognition Using a Smartphone as a Sensor Platform. 14th International IEEE Conference on Intelligent Transportation Systems. Washington, DC, USA, October $5-7$.

Jun, J., Ko, J., Yoon, S., \& Guensler, R. (2006). Impacts of Acceleration Calculation Methods on Onroad Vehicle Engine Power Estimation. 99th Air \& Waste Management Association Annual Meeting. New Orleans, Louisiana, June 20-23.

Klauer, S. G., Dingus, T. A., Neale, V. L., Sudweeks, J. D., \& Ramsey, D. J. (2009). Comparing Real-World Behaviors of Drivers With High versus Low Rates of Crashes and Near-Crashes. NHTSA Final Letter Report. Washington, DC, USA.

Lamm, R., Psarianos, B., \& Mailaender, T. (1999). Highway Design and Traffic Safety Engineering Handbook. McGraw-Hill.

Paefgen, J., Kehr, F., Zhai, Y., \& Michahelles, F. (2012). Driving Behavior Analysis with Smartphones: Insights 
from a Controlled Field Study. Proceedings of the $11^{\text {th }}$ International Conference on mobile and ubiquitous multimedia. Ulm, Germany, December 4-6.

Shaout, A. K., \& Bodenmiller, A. E. (2011). A Mobile Application for Monitoring Inefficient and Unsafe Driving Behaviour. International Arab Conference on Information Technology (ACIT 2011). Naif Arab University for Security Sciences, Riyadh, Saudi Arabia, December 11-14.

Sievert, W. (1994). The Influence of Modern Electronic Systems in Motor Vehicles on Accident Statistics. Journal for Traffic Safety, 2, 72-82.

Tonzig, G. (2011). Fondamenti di meccanica classica (3rd ed.). Maggioli Editore.

Vaiana R., Capiluppi G. F., Gallelli, V., Iuele, T., \& Minani, V. (2012). Pavement surface performance evolution: an experimental application. Procedia: Social \& Behavioral Sciences, 53, 1150-1161. http://dx.doi.org/10.1016/j.sbspro.2012.09.964

Yamakado, M., Takahashi, J., Saito, S., \& Abe, M. (2009). G-Vectoring: New Vehicle Dynamics Control Technology for Safe Driving. Industrial Systems, 58(7), December 2009.

Zhang, Y., Owechko, Y., \& Zhang, J. (2004). Driver Cognitive Workload Estimation: A Data-driven Perspective. 2004 IEEE Intelligent Transportation Systems Conference, October 3-6. Washington, D.C., USA.

\section{Copyrights}

Copyright for this article is retained by the author(s), with first publication rights granted to the journal.

This is an open-access article distributed under the terms and conditions of the Creative Commons Attribution license (http://creativecommons.org/licenses/by/3.0/). 